\title{
Inventory Control of return based on Fuzzy Theory of E-commerce
}

\section{environment}

\author{
Guogang $\mathrm{Li}^{1, \mathrm{a}}$ and Weiwei $\mathrm{Li}^{2, \mathrm{~b}}$ \\ ${ }^{1}$ School of Management of Tianjin technology University, Tianjin 300384, China; \\ ${ }^{2}$ School of Management of Tianjin technology University, Tianjin 300384, China. \\ alggcj@163.com, ㅁwwmuzili@163.com
}

Key words: returns inventory control; fuzzy theory; EOQ; E-commerce

Abstract: With the expansion of affecting area of e-commerce ,the enhance of purchasing power and the characteristics of goods make our return defective merchandise more and more serious, which directly affects the validity of the operation of the online sales channel inventory control. In this paper, with out of the amount, return rates, and other related variables for the fuzzy numbers, in order to minimize the total cost of the average stock as the objective function, the establishment of a return rates and shortage of fuzzy economic EOQ model and determine the optimal order quantity.

\section{Introduction}

E-commerce is widely used in the Internet and information technology under development, it is the growing demand of online shopping. According 100.EC.CN monitoring data show that the first half of 2015, online retail sales in the country has reached 1.6459 trillion yuan, an increase of $39.1 \%$. At the same time, the return can not be ignored problems have cropped up in the field of reverse logistics in return, inventory management research is essential. $\mathrm{Li}^{[1]}$ and $\mathrm{Kao}^{[2]}$, who set up a fuzzy model of single-cycle inventory problems. And Zhang Qun and Li Qunxia ${ }^{[3]}$ with trapezoid fuzzy number to describe the demand, purchase costs, ordering costs, holding costs and shortage costs, allow modest Out of stock model were studied. Wang Shengyu and Zhong Weiqing ${ }^{[4]}$ using fuzzy structured element method to study and solve the problem of fuzzy multi-objective decision making under conditions permit Out inventory model. Chang ${ }^{[5]}$ studied the EOQ model requirements and defect rates are fuzzy numbers when, in order to maximize profits as the objective function, and this model was solved after the best order quantity. Huang Zunqing ${ }^{[6]}$ who studied in consumer demand and allow the return and the return of consumers are subject to a separate inventory model Possion distribution results showed that the rate of return on the dealer's order quantity and the expected return had a significant effect. In this paper, the unit demand, return rates and other variables as fuzzy parameters to construct the average inventory total cost function, and then use the solution graded mean integration representation of the average total cost of inventory fuzzy value, and finally get the optimal order quantities based on the value of the derivative after .

\section{Inventory model parameters and underlying assumptions}

(1) Out of return rates and EOQ inventory model parameters and their meanings are shown in Tab1.

Tab.1 Parameters and their meanings

\begin{tabular}{c|c}
\hline variable & meaning \\
\hline $\mathrm{Q}$ & order amount \\
$\mathrm{B}$ & Out of the amount \\
$\mathrm{D}$ & Unit demand \\
$\mathrm{C}$ & The total cost of stock \\
$C_{z}$ & The average total cost of stock \\
$\mathrm{R}$ & Reorder point inventory levels \\
\hline
\end{tabular}




\begin{tabular}{c|c}
\hline $\mathrm{P}$ & Return rates \\
$P_{a}$ & Defective return rates \\
$P_{b}$ & Not satisfied with the product return rates \\
$C_{q}$ & Unit shortage cost \\
$C_{d}$ & The ordering cost per order \\
$C_{h}$ & Unit storage costs \\
\hline constant & meaning \\
\hline $\mathrm{T}$ & Inventory cycle \\
$\mathrm{L}$ & Lead time \\
$C_{t}$ & Unit inspection fees \\
$C_{g}$ & Unit purchase price \\
$C_{m}$ & Unit costs Return \\
\hline
\end{tabular}

(2) Basic assumptions

Suppose 1. Suppose the demand for units, out of the amount, rate of return, defective return rates, unit storage costs, unit shortage cost, cost-per-order fuzzy numbers.

Suppose 2. Suppose demand and returns are uniform, continuous

Suppose 3. Suppose return defective products affect the secondary sales returned to the supplier, not satisfied with the return product (without any product quality problems) into the secondary sales

Suppose 4. The stock dropped to assume, then began ordering lead time constant

Suppose 5. Allow out and orders after reaching out to complement the current amount immediately

Suppose 6. Only consider the case of a product

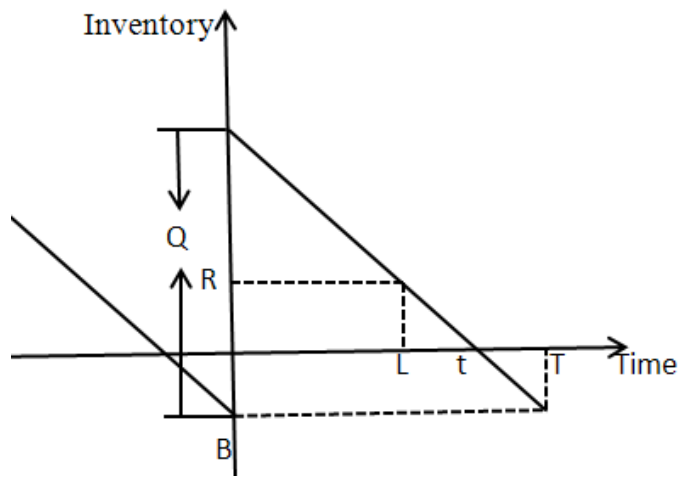

Fig.1 inventory changes

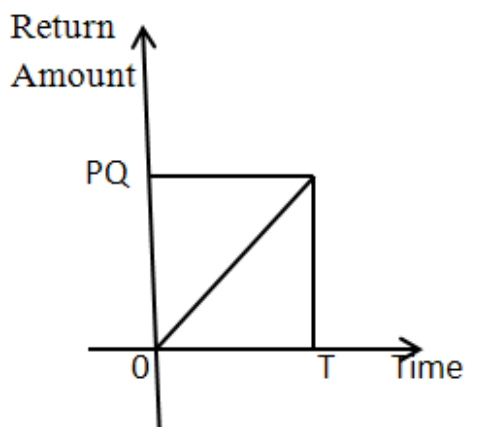

Fig.2 changes the amount of return

Figure 1 is considering ordering cycle stocks and out of the return rate in case of changes in the process, Figure 2 shows the amount of the return cycle process. As shown in Figure 1, when the inventory level reaches the start order, lead time is. After time, Inventory stocks from the highest $(Q-B)$ down to zero inventory quantity, But this time did not reach the end of the cycle time, external demand has continued, and the next cycle has yet to order, so the resulting stock out of stock. Suppose at the end of time $(T-t)$, out of the maximum amount of stock is $B$.As shown in picture 2, the amount of Returns are $P Q$ in period of $\mathrm{T}$, the average amount of the return is $P Q / 2$ in period of $\mathrm{T}$.

\section{Out of solving the return rates and Fuzzy EOQ Inventory Model}

1. Fuzzy sets and fuzzy membership function 
For our return reverse logistics inventory management, there is a lot of uncertainty, and accurate historical statistics difficult to collect, so people can only give vague speculation more fuzzy information obtained through. Fuzzy number is usually a fixed numerical value up and down changes, such as guessing a person's height, approximately 180 centimeters presumably, its meaning is that a person's height of 180 centimeters (for example, from 178 to $182 \mathrm{~cm}$ ) maximum likelihood, not less than a certain value (for example, $175 \mathrm{~cm}$ ), can not be higher than a certain value (for example, $185 \mathrm{~cm}$ ), such as the scope of such changes at $180 \mathrm{~cm}$ and down to form a fuzzy set. At this height it is vague, It can be represented by $\widetilde{D}=[175,178,182,185]$ symbol. In real life, each of the number of fuzzy sets appear as actual values are possible, but the possibility is not the same as the height of the fuzzy set membership function is constituted by the possibility. In this paper, trapezoidal reverse logistics for returned inventory study, shown in Figure 3.

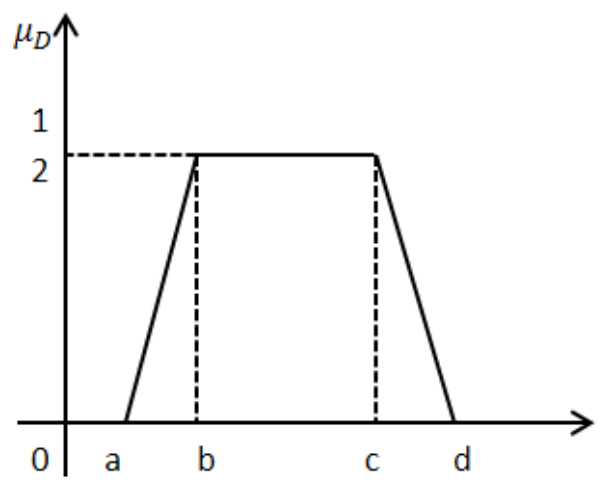

Its membership function is expressed as:

$$
\mu_{D}(D)= \begin{cases}0, ? & x \leq a, x>d \\ \frac{x-a}{b-a}, ? & a<x \leq b \\ 1, ? & b<x \leq c \\ \frac{d-x}{d-c}, ? & c<x \leq d\end{cases}
$$

Fig.3 trapezoid shape membership function fuzzy numbers

2.Fuzzy parameters and return rates 3.2 out of Fuzzy EOQ inventory model defuzzification

(1) Fuzzy Parameters

In real life, due to various reasons has sold products return, return goods stored in the warehouse and then storage costs thus caused; will return product inspection test to distinguish between costs and defective products caused not satisfied; the moment after a period of the order of arrival of the cycle to return defective products returned after the costs caused by the supplier, this model these factors are taken into account.

In this paper, the return rate and Out EOQ inventory model is based on the average total inventory cost as the objective function, the total cost of the inventory ordering costs per order, returned goods inspection costs, storage costs, shortage cost, and then return goods storage cost, substandard goods return costs, purchase price, return defective goods purchase cost components. And unit demand defective return rates, rates of return, Out of the amount, unit storage costs, unit shortage cost, cost-per-order fuzzy parameters,

Fuzzy stock average total cost: 


$$
\begin{aligned}
& \widetilde{C}_{z}=\left[C_{m} p_{a 1} d_{1}+C_{t} p_{1} d_{1}+C_{g} d_{1}-C_{g} d_{4} p_{a 4}\right. \\
& +\frac{\left(C_{h 1}+C_{q 1}\right) b_{1}^{2}+C_{h 1} Q^{2}+2 C_{d 1} d_{1}-2 C_{h 4} b_{4} Q}{2 Q}+\frac{C_{h 1} p_{1} Q}{2}, \\
& C_{m} p_{a 2} d_{2}+C_{t} p_{2} d_{2}+C_{g} d_{2}-C_{g} d_{3} p_{a 3} \\
& +\frac{\left(C_{h 2}+C_{q 2}\right) b_{2}^{2}+C_{h 2} Q^{2}+2 C_{d 2} d_{2}-2 C_{h 3} b_{3} Q}{2 Q}+\frac{C_{h 2} p_{2} Q}{2}, \\
& C_{m} p_{a 3} d_{3}+C_{t} p_{3} d_{3}+C_{g} d_{3}-C_{g} d_{2} p_{a 2} \\
& +\frac{\left(C_{h 3}+C_{q 3}\right) b_{3}^{2}+C_{h 3} Q^{2}+2 C_{d 3} d_{3}-2 C_{h 2} b_{2} Q}{2 Q}+\frac{C_{h 3} p_{3} Q}{2}, \\
& C_{m} p_{a 4} d_{4}+C_{t} p_{4} d_{4}+C_{g} d_{4}-C_{g} d_{1} p_{a 1} \\
& \left.+\frac{\left(C_{h 4}+C_{q 4}\right) b_{4}^{2}+C_{h 4} Q^{2}+2 C_{d 4} d_{4}-2 C_{h 1} b_{1} Q}{2 Q}+\frac{C_{h 4} p_{4} Q}{2}\right]
\end{aligned}
$$

(2) Defuzzification

In solving the fuzzy set this paper Chen and Hsieh ${ }^{[7]}$ proposed Graded Mean Integration Representation. Let a fuzzy number $\widetilde{C}=\left[c_{1}, c_{2}, c_{3}, c_{4}\right]$, according to their graded mean integration representation defuzzification value:

$$
P(\tilde{C})=\int_{0}^{1} h\left[\frac{c_{1}+c_{4}+\left(c_{2}-c_{1}-c_{4}+c_{3}\right) h}{2}\right] d h / \int_{0}^{1} h d h=\frac{c_{1}+2 c_{2}+2 c_{3}+c_{4}}{6}
$$

Formula (2) where $h$ is any change in the level of the value of membership within the interval.

According to equation (2) of the formula (1) Out of return rates and Fuzzy EOQ inventory model defuzzification, fuzzy average total cost of inventory and the resulting derivative can get out of the amount of blur:

$\widetilde{B}=\left[C_{h 1} Q /\left(C_{h 1}+C_{q 1}\right), C_{h 2} Q /\left(C_{h 2}+C_{q 2}\right), C_{h 3} Q /\left(C_{h 3}+C_{q 3}\right), C_{h 4} Q /\left(C_{h 4}+C_{q 4}\right)\right]$

Finishing available:

$$
\begin{aligned}
& P\left(\widetilde{C_{z}}\right)=\frac{1}{6}\left[C_{m} p_{a 1} d_{1}+C_{t} p_{1} d_{1}+C_{g} d_{1}-C_{g} d_{4} p_{a 4}+2\left\{C_{m} p_{a 2} d_{2}+C_{t} p_{2} d_{2}\right.\right. \\
& \left.+C_{g} d_{2}-C_{g} d_{3} p_{a 3}\right\}+2\left\{C_{m} p_{a 3} d_{3}+C_{t} p_{3} d_{3}+C_{g} d_{3}-C_{g} d_{2} p_{a 2}\right\} \\
& +C_{m} p_{a 4} d_{4}+C_{t} p_{4} d_{4}+C_{g} d_{4}-C_{g} d_{1} p_{a 1}-\frac{C_{h 4}^{2}}{C_{h 4}+C_{q 4}}-\frac{2 C_{h 3}^{2}}{C_{h 3}+C_{q 3}} \\
& \left.-\frac{2 C_{h 2}^{2}}{C_{h 2}+C_{q 2}}-\frac{C_{h 1}^{2}}{C_{h 1}+C_{q 1}}\right]+\frac{1}{12 Q}\left[\frac{C_{h 1}^{2}}{C_{h 1}+C_{q 1}}+\frac{2 C_{h 2}^{2}}{C_{h 2}+C_{q 2}}\right. \\
& \left.+\frac{2 C_{h 3}^{2}}{C_{h 3}+C_{q 3}}+\frac{C_{h 4}^{2}}{C_{h 4}+C_{q 4}}\right]+\frac{Q}{12}\left[C_{h 1}+C_{h 1} p_{1}+2\left(C_{h 2}+C_{h 2} p_{2}\right)\right. \\
& \left.+2\left(C_{h 3}+C_{h 3} p_{3}\right)+C_{h 4}+C_{h 4} p_{4}\right]+\frac{1}{6 Q}\left[C_{d 1} d_{1}+2 C_{d 2} d_{2}+2 C_{d 3} d_{3}+C_{d 4} d_{4}\right]
\end{aligned}
$$


Make $\frac{\partial P\left(\widetilde{C_{z}}\right)}{\partial Q}=0$, the average total cost of inventory can be obtained at the minimum optimal EOQ $Q^{*}$ :

$$
Q^{*}=\sqrt{\begin{array}{l}
2 C_{d 1} d_{1}+4 C_{d 2} d_{2}+4 C_{d 3} d_{3}+2 C_{d 4} d_{4}+\frac{C_{h 1}^{2}}{C_{h 1}+C_{q 1}}+\frac{2 C_{h 2}^{2}}{C_{h 2}+C_{q 2}} \\
\frac{2 C_{h 3}^{2}}{C_{h 3}+C_{q 3}}+\frac{C_{h 4}^{2}}{C_{h 4}+C_{q 4}}
\end{array}}
$$

\section{Consider and discuss return rate Out of Fuzzy EOQ Inventory Model}

1. When the unit demand fuzzy parameters, return rates, Out of the amount, unit storage costs, unit shortage cost, the cost of each order are constant,

That unit demand $d_{1}=d_{2}=d_{3}=d_{4}=d$, Return rate $p_{1}=p_{2}=p_{3}=p_{4}=p$, Unit storage costs, unit shortage cost, the cost of each order above. Put them into the equation (4), can get the best finishing $\mathrm{EOQ} Q^{*}$ is:

$$
Q^{*}=\sqrt{\left(2 d C_{d}+\frac{C_{h}^{2}}{C_{h}+C_{q}}\right) / C_{h}+p C_{h}}
$$

Then the above equation (5) for the deterministic case to consider the return rate and shortage of EOQ model.

The (5) in the return rate $\mathrm{P}=0$, you can get the best finishing EOQ is $Q^{*}$ :

$$
Q^{*}=\sqrt{\left(2 d C_{d}+\frac{C_{h}^{2}}{C_{h}+C_{q}}\right) / C_{h}}
$$

Then the above equation (6) for the deterministic case without considering the return rate is only considered out of the EOQ model.

2. When there is no return, and out of the unit cost of infinity, that is, the rate of return $P=0$ and $\lim C_{q} \rightarrow \infty$.

Put them into the equation (4), can get the best finishing EOQ $Q^{*}$ as follows:

$$
Q^{*}=\sqrt{2 d C_{d} / C_{h}}
$$

Then the above equation (7) for the classical EOQ model.

\section{Summary}

Taking into account the situation of returned products, so the application of the classical EOQ model is somewhat limited. In this paper, fuzzy set theory, fuzzy consider more parameters and return rates Out Fuzzy EOQ model, the solution method for solving fuzzy, fuzzy parameters results show that more cases could reasonably solve inventory control problems. In this model, if all fuzzy parameters can be replaced with the actual values, the formula is the best formula EOQ (5). 
Inventory model discussed in this paper module, validated when not considering return rates and stock, is the traditional EOQ model, consider the return rate and shortage of fuzzy EOQ model it is reasonable and feasible.

\section{References}

[1] Li L S, Kabadi S N, Nair K P. Fuzzy Models for Single-period Inventory Problem [J] .Fuzzy Sets and Systems, 2002 (132): 273-289.

[2] Kao C, Hus W K. A Single-period Inventory Model with Fuzzy Demand [J] .Computer and Mathematica with Applications,2002(43):841-848.

[3] Zhang Qun, Li Qunxia. Fuzzy Inventory Model with Backorder and Its Optimum Solution [J] .Journal of Management, 2006,3 (4): 460-464.

[4] Wang Shengyu, Zhong Weiqing. Allow fuzzy inventory model out of the optimal solution with multi-objective programming[J].Liaoning Technical University (Natural Science), 2013,32 (7): 1004-1008.

[5] Chang, H C. An Application of Fuzzy Sets Theory to the EOQ Model with Imperfect-quality Items[J]. Computers and Operations Research, 2004,31:2079-1092.

[6] Huang Zuqing, Da Liqing. Allow a return of the stock control strategy model [J]. Southeast University (Natural Science), 2003,33 (6): 792-795.

[7] Chen S H, Hsieh C H. Graded Mean Integration Representation of Generalized Fuzzy Number [J]. Journal of Chinese Fuzzy System, 1999,5 (2):1-7. 